\title{
Expertise and Data in the Articulation of Risk
}

\section{ARST Preconference Session Report}

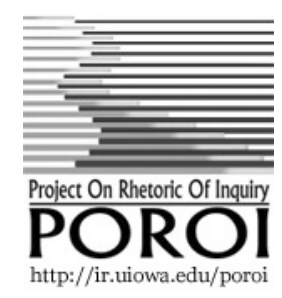

Ashley Rose Kelly

University of Waterloo

Waterloo, $\mathrm{ON}$

Carolyn R. Miller

North Carolina State University

Raleigh, NC

Shannon N. Fanning

Iowa State University

Ames, IA

Molly M. Kessler

University of Wisconsin-Milwaukee

Milwaukee, WI

\section{S. Scott Graham}

University of Wisconsin-Milwaukee

Milwaukee, WI

\section{Daniel J. Card}

University of Wisconsin-Milwaukee

Milwaukee, WI

Poroi 11,1 (May 2015)

Keywords: rhetoric of science and technology, rhetoric of health and medicine, risk society, risk communication, visual rhetorics, democratization

At the 2014 Association for the Rhetoric of Science and Technology pre-conference at the National Communication Association, the "Expertise and Data in the Articulation of Risk" panel featured several papers concerned with how risk is communicated to publics and how publics respond to those articulations of risk. Each paper provided different perspectives and cases that concerned why communication of complex scientific and medical information about risks seems to fail and some insights into how to better communicate risks. Here we provide a short overview of each paper's argument, central findings, and recommendations. We then 
discuss some key themes of the rhetoric of science, technology, and medicine (RSTM) from each case.

\section{ARGUMENTS ABOUT ARTICULATING RISK}

In her paper "Trusting Experts: The Rhetoric of Risk Communication," Carolyn R. Miller reviewed the development of risk communication as a research field and a professional practice and explored its rhetorical dimensions. Originating in the debate over nuclear power in the 1960s, risk communication was well funded by private enterprise and by the National Science Foundation in the 1970 s and 1980s, producing a great deal of social science on the construction of risk messages and their acceptance by public audiences. However, it can claim little practical success at changing the public mind in specific cases. This research has identified trust as a key variable that plagues risk communication campaigns (Slovic, 1993; Lofstedt, 2003). Rhetoricians recognize trust as a function of rhetorical ethos, and an analysis of ethos can help diagnose the problem of public trust. Some of the early risk communication research in fact drew on Aristotle's analysis to conceptualize the multiple dimensions of trust (Kasperson, 1986; Peters et al., 1997). In practice, risk communication is a program focused on the deployment of information and expertise, that is, the kind of proof Aristotle called logos and the dimension of ethos he identified as phronêsis. The failure of risk communication to recognize the importance of pathos and ethos, and specifically the dimensions of ethos that Aristotle called arête and eunoia, in developing and maintaining trust, makes the rhetorical ineffectiveness of much official risk communication entirely predictable.

Another frequently noted feature of trust is its asymmetry, illustrated in the adage that it "arrives on foot but leaves on horseback." This can be understood as a function of rhetorical presumption. As Aristotle pointed out, on matters "where there is not exact knowledge but room for doubt," we must rely on ethos. In such cases, a persuasive ethos can gain the presumption, and an unpersuasive ethos may make the burden of proof for an uncertain claim insurmountable. This makes ethos, as Aristotle tells us, "almost, so to speak, the controlling factor in persuasion" (Aristotle, Rhetoric, I.2.iv, trans. Kennedy). Thus, we are predisposed to be sensitive to indications of character: Since we must rely on it so heavily, we cannot afford to make mistakes. We are vulnerable to the indeterminacy of the world and to the character flaws and intentions of others. Given the ongoing dynamics of the public response to expertise, changing burdens of proof in specific cases, 
and the widespread philosophical and political interest in trust, a re-examination of the rhetorical functioning of trust between experts and publics seems warranted, and in this effort, Aristotelian rhetoric can offer some guidance to the dilemmas of risk communication.

Ashley Rose Kelly, in her "Open Risk Assessment: Rhetorical Expansion of Expert Ethos," argues that advocates of open technology and data are reconfiguring risk assessment roles by developing new sensor technologies to monitor risks associated with natural and human-made hazards. Further, by using open technologies, advocates of open hardware, software, and data are challenging the distinction between expert and non-expert on the grounds of risk assessment (see also Kelly, 2014; Kelly and Miller, forthcoming). Development of open hardware devices, open software applications, and publication of public-domain data allows for expert ethos to be extended beyond the traditional sphere of career scientists. In conducting this work, these advocates engage in what is essentially ethotic construction of a new kind of expert by challenging certain premises of who is capable of-and who ought to be-assessing modern technoscientific risks (Beck, 1992).

To investigate how this ethotic work is accomplished, Kelly provided a case study of a grassroots project to measure radiation contamination following the disaster at Fukushima Daiichi. In the four years since the disaster at Fukushima began, a grassroots organization called Safecast has collected over 25 million data points measuring radiation contamination, as well as coordinating locational and temporal data. How this group formed, organized, and activated illustrates how non-experts can move into an expert role, suggesting that the route to expertise through career science has perhaps been destabilized. Research into the changing relationship between publics, experts, and ownership of technoscientific expertise has continued in RSTM's allied fields of science studies through second wave concerns with democratization to third wave concerns with the nature of expertise (Collins and Evans, 2002). Attending to the rhetorical dimensions of expertise positions rhetorical studies of science and technology to intersect more strongly with these allied fields.

Shannon N. Fanning's presentation, "Rhetoric and Risk in DataDesign: Correlation, Causation, and the Autism/Vaccination Debate," address mistaken attributions of causality in data visualizations used within the context of the autism/vaccination controversy. Drawing on sources from cognitive psychology, which have explained why people seek out causal relationships (Beitman, 2009; Whitson and Galinsky, 2008), and from visual rhetoric, 
which have addressed perceptual issues with charts and graphs (Kostelnick, 2007; Tufte, 2001), Fanning suggests four rhetoricallyrooted hypotheses regarding reader/viewers' susceptibility to the misinterpretation of causality: the social construction of monsters, the illusion of choice and control, the power of allies, and the hyperdemocratization of data. After presenting these possible explanations, Fanning uses them to examine a series of visuals that present data on the possible connection between autism and vaccination.

Through her study of visuals, Fanning draws some preliminary conclusions regarding viewers' susceptibility to "seeing" causation in data visualizations. She argues that these visuals rely on the support of allies, allies that in many cases support false understandings of the data, leading to misinterpretation. Through the rhetoric of fear they employ, the graphs examined also invite the construction of vaccines as monsters, a displacement of fear that requires quick action to seize the kairotic moment before the ability to locate this fear externally expires. This quick call to action prevents viewers from looking at the relationships between the data critically, making them more susceptible to misinterpretation. This fear may also lead to illusory pattern perception, the result of which is seeing relationships in the data that do not really exist. Finally, Fanning suggests that all of these issues are exacerbated by the "hyperdemocratization" of data: As viewers are presented with far more data than they can ever fully hope to comprehend, the likelihood of misinterpretation and mistaken attribution of causality increases.

A collaborative presentation by the University of WisconsinMilwaukee's Scientific and Medical Communications Laboratory (SAMComm), entitled "Packaging Innovation Adoption: A Rhetorical-Ethnography of Continuing Medical Education," provides results from a mix-methodological pilot study of risk communication in continuing medical education. The study provided findings from ethnographic observations and survey data collected at the BMT Tandem Meetings-the premiere international convention for the Center for International Blood and Marrow Transplant Research and the American Society of Bone Marrow Transplantation. The presentation builds on preexisting research indicating that although Randomized Controlled Trials (RCTs) and risk-benefit ratios serve as the medical community's evidentiary gold standard, presenting this risk data in isolation is neither an effective nor a persuasive mode of presentation (Teston, Graham, Baldwinson, Li, and Swift, 2014). 
SAMComm researchers observed over 50 presentations and were provided access to recordings for several hundred others that occurred during the weeklong convention. They further administered a survey to determine which presentations attendees thought were most valuable, and using these results as a guide, the research team collected the recordings of these presentations for further analysis. Specifically, SAMComm identified and described a number of "modes of calibration" at work in the exemplar presentations (Mol, 2002; Graham, 2015). Findings suggest that calibration of risk data with evidence and/or resources that extend beyond RCTs improves the communication of risk. For example, presentation content and formats that engaged participants in translational discussion where basic science and clinical trial data are calibrated to case studies and/or reflections on clinical experience were common features of those presentations identified as most valuable. This finding is consistent with other studies that indicate calibrating presentations are more likely to encourage innovation adoption than presentations in which a single format or mode of presentation is delivered (Graham, 2015).

\section{EMERGING QUESTIONS ABOUT THE RHETORICS OF RISK}

One of the issues raised in the panel discussion concerned the implications and entailments of the analytical vocabulary applied in understanding risk and risk communication, with the papers by Miller and SAMComm team highlighting the point. Miller's reliance on the classical, Aristotelian vocabulary was questioned, given its roots in a pre-modern society with much simpler institutions and risks. She, in turn, questioned what was gained by the materialist science-studies vocabulary preferred by the SAMComm team, contending that one could substitute classical rhetoric for many of the analytical terms derived from the work of Mol (and indirectly Latour) (Mol, 2002). A practical approach seemed best: Which vocabulary helps the researcher see and understand in new and productive ways? Which vocabulary will help the research communicate results to relevant audiences?

But a practical approach concerning communicating results reminds us that neither Aristotelian nor contemporary theoretical vocabularies will have much translational effect outside of fields attending to those conversations. For example, what does "inscription" signify to the typical geneticist? Certainly not what it means to the science studies scholar-instead, perhaps, it means the process of gene encoding. As a point of concern this reminds us of more than our own disciplinary ball games. Rather the concern 
with vocabulary-our jargon, our shorthand-suggests that the project of engaging scientists, policy-makers, health care practitioners, etc., requires us to consider the nature of expertise. What we, as rhetoricians and science studies scholars, communicate to "relevant audiences" is likely to be accommodated, to borrow Jeanne Fahnestock's term (Fahnestock, 1986). As in other fields of inquiry, we commit and align ourselves to traditions with these choices. We then find an exigence for a reflexive conversation. Scientists use jargon, scientists accommodate, scientists confuse publics with specialized language (e.g., "manipulation," "correlation," etc.) and logical but counterintuitive visuals (see Fanning, above).

A practical approach to research might suggest a vocabulary that helps the researcher see and understand in new and productive ways. But a practical approach to communicating results to various relevant audiences requires a different vocabulary. And when the public moves into scientific spheres, when they attempt to engage the vocabulary that helps the researcher see and understand in new and productive ways, additional vocabularies may emerge. Divisions between science and its publics are increasingly problematic as distinctions between the inner world of scientific research and the external world of technological application/social norms merge in late modernity. Questions of trust in experts permeate discussions of risks, particularly inequitable distributions of risks as described by the late Ulrich Beck (Beck 1992, 2008). Sometimes tensions between declared experts and those challenging their status, such as medical and epidemiological experts and anti-vaccine proponents, make visible the complicated relationship between science and publics. Sometimes, too, productive alliances between those once on the outside, publics, and career scientists generate and encourage different kinds of knowledge production, such as citizen science. Career scientists and citizen scientists, and certainly charlatans too, complicate the landscape for the production and dissemination of scientific knowledge. Within this increasingly complex landscape are possibilities for better kinds of science, new ways of integrating different types of knowledge, but misunderstanding and misinformation are also scattered about as possibilities for confusion and controversy. There are more "stakeholders" still.

The SAMComm team was asked what the influence of pharmaceutical companies might be on these conferences. How does information come to be shaped by corporations, by the truly career scientists and businesspersons? Here again loom Miller's issues of trust not only in science, but in the complicated apparatus 
of late modern technoscience, the instrumental arm where business and science are married for "pragmatic" application of scientific knowledge. Interests and investments of business, or even of governments, further complicate how science and the production of scientific knowledge are disseminated and understood, accepted or rejected. Rhetorics of science, we might argue, have never been so salient, as scientific, technical and medical discourses, and discourses around those subjects, become increasingly complex and the rhetors from increasingly diverse perspectives make themselves heard. Indeed, rhetoric offers some valuable tools for dialectic in the polysemic spheres of discourse we find in the cases discussed in this panel.

\section{IMPLICATIONS FOR RHETORICS OF SCIENCE, TECHNOLOGY, AND MEDICINE}

As rhetorical studies of science and technology expand to include health and medicine, the field's application to complex technoscientific contexts increases. What rhetoricians can tell scientists, physicians, and engineers about how information is crafted and communicated is increasingly important as, for example, consequences of anti-vaccine sentiments showed us only months after this panel, when the United States saw a large outbreak of measles (CDC, 2015). At the same time, giving voice to the publics with which scientists, physicians, and engineers attempt to communicate remains an important site of engagement for rhetoricians. We are, as Leah Ceccarelli illustrated in her 2011 "Manufactured Scientific Controversy" and again argued during the 2014 NCA ARST conference, in a precarious place as rhetoricians, "selling our wares" to sometimes competing interests. But it is in just this precarious situation that we find a space for rhetoricians of science, technology, and medicine to ground their work in uncovering the tools of argument, of persuasion and dissuasion, that make up the complicated communicative landscape of late modernity's technoscientific risk societies.

\section{REFERENCE LIST}

Aristotle. On Rhetoric: A Theory of Civic Discourse. George A. Kennedy (Trans.) 2nd ed. New York: Oxford University Press, 2007.

Beck, U. World at Risk. Malden, MA: Polity, 2008.

Beck, U. Risk Society: Towards a New Modernity. Thousand Oaks, CA: Sage Publications, 1992. 
Beitman, B. D. "Brains Seek Patterns in Coincidences." Psychiatric Annals 39 (2001): 255-264.

Ceccarelli, L. "Manufactured Scientific Controversy." Rhetoric and Public Affairs 14 (2011): 195-228.

CDC (Centers for Disease Control and Prevention). "Measles Cases and Outbreaks." Centers for Disease Control and Prevention-Measles (Rubeola), 2015: http://www.cdc.gov/measles/cases-outbreaks.html

Collins, H.M. and R. Evans. "The Third Wave of Science Studies: Studies of Expertise and Experience." Social Studies of Science 32 (2002): 235-296.

Fahnestock, J. "Accommodating Science: The Rhetorical Life of Scientific Facts." Written Communication 3 (1986): 275296.

Graham, S.S. The Politics of Pain Medicine. Chicago, IL: University of Chicago Press, 2015.

Kasperson, R. E. "Six Propositions for Public Participation and Their Relevance for Risk Communication." Risk Analysis 6 (1986): 275-81.

Kelly, A.R. Hacking Science: Emerging Parascientific Genres and Public Participation in Scientific Research. Dissertation. Raleigh, NC: NCSU Institutional Repository, 2014.

Kelly, A. R. and C. R. Miller, "Intersections: Scientific and Parascientific Communication on the Internet." Science and the Internet: Communicating Knowledge in a Digital Age (pp. 333-380). Baywood Press, forthcoming.

Kostelnick, C. "The Visual Rhetoric of Data Displays: The Conundrum of Clarity." IEEE Transactions on Professional Communication 50 (2007): 280-294.

Lofstedt, R. "Risk Communication: Pitfalls and Promises." European Review 11 (2003): 417-35.

Mol, A. The Body Multiple: Ontology in Medical Practice. Durham, NC: Duke University Press, 2002.

Peters, R. G., V. T. Covello, and D. B. McCallum. "The Determinants of Trust and Credibility in Environmental Risk Communication: An Empirical Study.” Risk Analysis 17 (1997): 43-54.

Slovic, P. "Perceived Risk, Trust, and Democracy." Risk Analysis 13 (1993): 675-82. 
Teston, C.B., S.S. Graham, R. Baldwinson, A. Li, and J. Swift. "Public Voices in Pharmaceutical Deliberations: Negotiating 'Clinical Benefit' in the FDA's Avastin Hearing." Journal of Medical Humanities 35 (2014): 149-170.

Tufte, E. R. The Visual Display of Quantitative Information. 2nd ed. Cheshire, CT: Graphics Press, 2001.

Whitson, J. A. and A. D. Galinsky. "Lacking Control Increases Illusory Pattern Perception.” Science 322.5898 (2008): 115117. 